\title{
Millimetre-Wave Aperture Synthesis Radiometry for Snow and Ice Mapping
}

\author{
Andy R Harvey ${ }^{1}$, Alan H Greenaway ${ }^{2}$, Adriano Camps $^{3}$, Ignasi Corbella ${ }^{3}$, Francesc Torres ${ }^{3}$, Javier Bará $^{3}$, \\ and Manuel Martin-Neira ${ }^{4}$ \\ ${ }^{1}$ Dept. Aerospace, Power and Sensors, Cranfield University, Shrivenham, Swindon SN6 8LA, UK \\ Tel +44 (0)1793 785215, Fax +44 (0)1793 785260, e-mail a.r.harvey@rmes.cranfield.ac.uk \\ ${ }^{2}$ Defence Research and Evaluation Agency, St Andrews Rd., Malvern, Worcs., WR14 3PS, UK \\ ${ }^{3}$ Dept. of Signal Theory and Communications, Universitat Politecnica de Catalunya, Barelona, Spain, \\ ${ }^{4}$ ESTEC, Postbus 299, 2200 AG Noordwijk, The Netherlands
}

\section{INTRODUCTION}

Recent years have witnessed a growing interest in passive microwave and millimetre wave imaging for space-based remote sensing of geophysical parameters and features. Applications include measurement and classification of snow and ice cover []1, sea and land surface temperatures, sea surface salinity, soil moisture content and wind velocity [2]. Mechanical, mm-wave pencil beam scanners, such as AMSR and SMMR have previously been employed for earth observation, but for ground resolutions of a few kilometres launching and deploying the large antennas required becomes increasingly problematic. We address here the design of a thinned-array synthetic aperture interferometric radiometer (SAIR) for dual application to (1) mapping of snow and ice cover and (2) determination of ocean wind vector.

The most mature research programmes for Earth observation using radio-frequency aperture synthesis are ESA's MIRAS programme [3] and NASA's ESTAR programme [4] that both operate at L-band. The former uses a two-dimensional Y-shaped array of circular antennas whereas the latter employs a linear array of stick antennas that is pushbroom scanned to form a two-dimensional image. Other candidate techniques are the Mills Cross [5] the closely related RadSAR [6] and supersynthesis [7] techniques and hybrid techniques combining a slow conical scan with one- and twodimensional aperture synthesis such as the so-called QUARTZ technique [8]. Mm-wave SAIR for Earth observation is also pertinent to terrestrial real-time mmw imaging $[9,10]$ for applications such as detection of land mines, foul weather flying aids and surveillance. In seeking to extend these microwave SAIR techniques to mm-wave frequencies it is crucial to consider the ramifications of operation at higher $\mathbf{m m}$-wave frequencies in terms of the increased demands on component specifications and the greatly increased costs.

\section{COMPARISON OF MM-WAVE SAIR TECHNIQUES}

The main challenge in designing a SAIR system is to achieve the technical requirements with acceptable complexity: parameters such as sensitivity and field of view can only be

This work was funded by ESA contract 12549/97/NL/NB improved at the expense of increased system complexity and cost. It is therefore important that a cost-efficient system is designed with a performance that is necessary and sufficient for the scientific task. The technical requirements for a SAIR to map snow and ice and to measure ocean wind vector are summarised in Table 1 . Table 2 summarises the salient parameters that discriminate between the most pertinent SAIR architectures when designed to meet the snow and ice mapping requirements at $31.5 \mathrm{GHz}$. Similar differences exist between the systems for operation at $89 \mathrm{GHz}$. The SAIR architectures parameterised are the Mills Cross, twodimensional aperture synthesis using a $\mathrm{Y}$ array (as for MIRAS) in both a pushbroom and conical scan, onedimensional aperture synthesis using a conical scan and subarrayed antennas (QUARTZ) and one-dimensional aperture synthesis with a pushbroom scan (ESTAR). Dimensions of the antenna arrays vary slightly between the different architectures, but for an angle of incidence of $50^{\circ}$ and Hamming weighting with a $-6 \mathrm{~dB}$ edge taper, the arrays are typically about $3 \mathrm{~m}$ parallel to the orbital velocity vector and $1.7 \mathrm{~m}$ in the transverse direction.

The use of a conical scan enables the instantaneous field of view to be decreased to reduce electronic complexity at the cost of increased mechanical complexity. The additional use of sub-arraying enables particular small fields of view with efficient suppression of alias responses. The quoted bandwidth $B$ is either the width of the radio-quiet window or the bandwidth required to achieve the stated sensitivity. The parameters $N_{\text {correlators, }} N_{\text {antennas }}$ and $N_{\text {receivers }}$ are the required numbers of correlators, antennas and receivers and taken together with the $B . N_{\text {correlators }}$ product form a measure of the complexity of the SAIR system. It is clear from these data that one-dimensional aperture synthesis with a pushbroom scan offers the highest performance with the lowest complexity. The salient reasons for this is that the minimum number of required pixels are formed and this leads to both reduced complexity and improved sensitivity (radiometric resolution is proportional to the square root of the number of baselines contributing to each pixel [11]). It is also clear that the complexity as defined by the above metrics is an order of magnitude higher for $89 \mathrm{GHz}$ system than for the $31.5 \mathrm{GHz}$ system and one must consider whether this is justified by the 
Table 1 Technical requirements for ocean wind vector and snow and ice mapping

\begin{tabular}{|l|l|}
\hline Orbit altitude & $800 \mathrm{~km}$ \\
\hline Angle of incidence, 9 & $\sim 50^{\circ}\left(40^{\circ}<9<65^{\circ}\right)$ \\
\hline Swath width & $>1300 \mathrm{~km}$ \\
\hline $\begin{array}{l}\text { Centre operating frequency } \\
\text { snow \& ice }\end{array}$ & $31.5 \mathrm{GHz} \& 89 \mathrm{GHz}$ \\
ocean wind vector & $31.5 \mathrm{GHz}$ \\
\hline Available bandwidth & $0.4 \mathrm{GHz}$ at $31.5 \mathrm{GHz}$ \\
& $2.4 \mathrm{GHz}$ at $89 \mathrm{GHz}$ \\
\hline Polarisation & \\
snow \& ice & Horizontal and vertical \\
ocean wind vector & Full Stokes parameters \\
\hline Spatial resolution & \\
snow \& ice & $6 \mathrm{~km}$ at $31.5 \mathrm{GHz}$ \\
& $2.5 \mathrm{~km}$ at $89 \mathrm{GHz}$ \\
ocean wind vector & $50 \mathrm{~km}$ at $31.5 \mathrm{GHz}$ \\
\hline Radiometric resolution & \\
snow \& ice & $1 \mathrm{~K}$ \\
ocean wind vector & $0.05 \mathrm{~K}$ \\
\hline Radiometric accuracy & $2 \mathrm{~K}$ \\
\hline
\end{tabular}

increased resolution and the marginal improvement in snow and ice classification.

\section{SYSTEM DESIGN}

In this section we describe the outline design for a polarimetric, mm-wave SAIR. One-dimensional aperture synthesis employs a hybrid technique in which a long linear array of real-aperture stick antennas form over-lapping fan beams on the ground and aperture synthesis within the fan beams enables synthesis of the mm-wave image. Critical aspects for building a high-resolution, mm-wave ESTAR are system calibration and the construction of stick antennas that will be $3 \mathrm{~m}$ long and about half a wavelength wide.

Mm-wave stick antennas

The most appropriate technology for implementing the stick antennas is a co-phased array of slotted-waveguide leaky-wave antennas. These have less sensitivity to frequency tuning than continuous leaky-wave antennas, lower loss than corporate fed dipole arrays and lower bulk than a co-phased array of pillbox antennas [12].

At $89 \mathrm{GHz}$ the high attenuation of fundamental-mode waveguide limits the length of a simple slotted waveguide antenna to less than $1 \mathrm{~m}$ and frequency tuning of the antenna pattern across the full bandwidth $B$ would be typically more than five times the width of the antenna pattern of a three metre long antenna. Combining the antennas into a co-phased array reduces the Ohmic losses, whilst the frequency tuning of each element is manifested as aperture plane phase aberration that increases sidelobe levels. To attain sidelobe levels in the real aperture direction that are below $-20 \mathrm{~dB}$, five elements are required for operation at $31.5 \mathrm{GHz}$ and 20 elements are required at $89 \mathrm{GHz}$. This is the reason for the increased numbers of receivers shown in columns five and six of Table 2. The aperture efficiency of the antennas is then predicted to be over $84 \%$ and broadening of the antenna pattern due to frequency-tuning is less than $0.3 \%$ at both frequencies. For polarimetric operation it will be necessary to employ interleaved arrays of horizontally and vertically polarised slotted waveguides $[13,14]$ within the inter-element spacing of 0.82 wavelengths that is necessary to position the first alias responses above the Earth's horizon.

To avoid resonances within the antenna structure the antenna pattern of a slotted waveguide antenna should be displaced from broadside by a few degrees and this requires a small compensatory increase in antenna length to maintain angular resolution. It might be noted that the set of vectors from the array to the far-field then describes a cone rather than a plane. This fact can be exploited to reduce the variation of angles of incidence across the swath width so as to improve the conditioning of the data inversion used for snow and ice classification. As an extreme example, if the stick antennas are co-aligned with the nadir vertical and the beam is tilted to $43^{\circ}$ from broadside, the angle of incidence is a constant $50^{\circ}$ across the swath width. The penalty however is a $37 \%$ increase in length of the antennas. and hence of the number of elements and receivers.

Table 2 Important parameters for the most viable mm-wave SAIR techniques at 31.5 GHz. For ESTAR, the preferred technique, parameters are shown for $31.5 \mathrm{GHz}$ and $89 \mathrm{GHz}$.

\begin{tabular}{|l|c|c|c|c|c|c|}
\hline \multirow{2}{*}{ Parameter } & \multirow{2}{*}{$\begin{array}{l}\text { Mills } \\
\text { Cross }\end{array}$} & \multicolumn{2}{|c|}{ 2D AS } & \multirow{2}{*}{ QUARTZ } & \multicolumn{2}{c|}{ ESTAR } \\
\cline { 3 - 4 } \cline { 5 - 7 } & & Pushbroom & $\begin{array}{c}\text { Conical } \\
\text { scan }\end{array}$ & & $31.5 \mathrm{GHz}$ & $89 \mathrm{GHz}$ \\
\hline$B(\mathrm{MHz})$ & 400 & 400 & 400 & 400 & 75 & 445 \\
\hline$N_{\text {correlators }}$ & 19,602 & 69,337 & 121,837 & 266 & 832 & 2044 \\
\hline $\begin{array}{l}B . N_{\text {correlators }} \\
(\mathrm{GHz})\end{array}$ & 7,841 & 27,735 & 48,735 & 233 & 62.4 & 910 \\
\hline$N_{\text {antennas }}$ & 297 & 322 & 427 & 20 & 25 & 42 \\
\hline$N_{\text {receivers }}$ & 297 & 322 & 427 & 100 & 125 & 1680 \\
\hline$\Delta T(\mathrm{~K})$ & 2.4 & 4.4 & 2.2 & 1.5 & 1 & 1 \\
\hline
\end{tabular}


Calibration

Calibration has been identified as a major problem for both one-dimensional [15] and two-dimensional [16] Earthobservation SAIRs. It is convenient to consider calibration in two parts: complex transmission from the front-end to the correlators and errors in the transmission function of the antenna array. The former, electronic calibration, can be accomplished using front-end noise injection [17]. Calibration of the antenna transmission can be accomplished using the Gmatrix method [18] which requires the measurement of the impulse response of each antenna pair for the complete field of view - that is to say, it cannot be fully characterised using a single noise source. To achieve a radiometric accuracy of $1 \mathrm{~K}$ requires knowledge of the relative physical shape of the antenna array to within one thousandth of wavelength $[15,19]$ and this can be achieved by free-space or optical-fibre interferometry [20,21]. Antenna calibration is thus achieved in two stages: (1) measurement of the full set of antenna pair impulse responses for a measured antenna shape and (2) prediction of the impulse response using modelling and realtime measurement of antenna shape.

\section{CONCLUSIONS}

An outline design for a dual-band $\mathrm{mm}$-wave polarimetric SAIR has been presented and is considered to be tractable. The envisaged application is for snow and ice mapping and ocean wind vector measurement. The vastly increased complexity of the high-frequency waveband may not be justified by the scientific benefit and operation at an additional lower frequency such as $18 \mathrm{GHz}$ may give improved classification, though with reduced spatial resolution.

\section{REFERENCES}

1. IEEE Trans, Geosci., Rem. Sen. 36, special edition, (1998)

2. N Skou, B Laursen, 'Measurement of ocean wind vector by an airborne, imaging polarimetric radiometer', Rad. Sci., 33, 3, pp 669-675, (1998)

3. M Martin-Neira, J M Goutoule, A Knight, J Claude, J Bara, A Camps, F Torres, I Corbella, A Lannes, E Anterrieu, B Laursen, N Skou, 'Integration of MIRAS breadborad and future activities', pp 869-871, IGARSS (1996)

4. D M Le Vine, A J Griffis, C T Swift, T J Jackson, 'ESTAR: A synthetic aperture microwave radiometer for remote sensing applications', Proc. IEEE 82, 12, pp 17871801, (1994)

5. H A Maillot, ' A cross beam interferometer for high resolution microwave sensing', Proc. IEEE Aerospace App. Conf., pp 77-86, (1993)

6. C Edelson, 'Applications of synthetic aperture radiometry', Proc. IGARSS, pp 1326-1328, (1994)
7. K Komiyama, 'Indoor experiment of two-dimensional supersynthesis radiometer', Proc. IGARSS, pp 1329-1331, (1994)

8. M Martin-Neira, J. Font-Rossello, 'Mechanically scanned interferometeric microwave radiometer using subarraying', ESTEC Internal Report, XR1/108.97/MMN, October 1997.

9. A R Harvey, R. Appleby, P Coward, A H Greenaway, R Anderton, G Hawkins, 'Electronic beam-steering for passive millimetre-wave imaging', Proc. $4^{\text {th }}$ Int. Conf. on mm \& submm-waves and applications, SPIE 3465, San Diego, July 20-23, (1998)

10. P M Blanchard, A H Greenaway, A R Harvey, K Webster, J Lightwave Technology, 17, 3 (1999) (In press)

11. C S Ruf, C T Swift, A B Tanner, D M Le Vine, 'Interferometric synthetic aperture radiometry for the remote sensing of the Earth', IEEE Trans. GeoSci. Rem Sens. 26 5, pp 597-611 (1988)

12. A R Harvey, A H Greenaway, 'Final Report on mm-wave aperture synthesis techniques', DERA report to ESTEC on contract 12549/97/NL/NB

13. L Josefsson, C G M van Klooster, 'Dual-polarised slotted waveguide SAR antenna', Proc. IEEE Symp. Ant. Prop pp 625-628, (1992)

14. A G Derneryd, A Lagerstedt, 'Novel slotted waveguide antenna with polarimetric capabilities', Proc. IEEE Symp. Ant. Prop. pp 2054-2056 (1995)

15. D E Weissman, D M Le Vine, 'The role of mutual coupling in the performance of synthetic aperture arrays', Rad. Sci., 33, 3, pp 767-779, (1998)

16. A Camps, R Torres, I Corbella, J Bará, P de Paco, 'Mutual coupling effects on antenna radiation pattern: an experimental study applied to interferometric radiometers', Rad. Sci., 33, 6, pp 1453-1552, (1998)

17. F Torres, A Camps, J Bara, I Corbella, R Ferrerro, 'Onboard phase and modulus calibration of large aperture synthesis radiometers: study applied to MIRAS', IEEE Trans. Geosci. Rem. Sen. 34, 4, pp 1000-1009, (1996)

18. A B Tanner, C T Swift,'Calibration of a synthetic aperture radiometer', IEEE Trans. GeoSci. Rem. Sen. 31, 1, pp 257-267, (1993)

19. F Torres, A Camps, J Bara, I Corbella, ' Impact of antenna errors on the radiometric accuracy of large aperture synthesis radiometer", Radio Science, 32, 2, pp 629-641 (1997)

20. Burnett J G, Erry G R G, Dickson R, McBride R, Gander $M$, Jones J D C, Blanchard P M, Greenaway A H, Harvey $A$, 'Channelled spectrum interrogation of an all fibre broadband interferometric differential strain sensor', European Workshop on Optical Fibre Sensors, 3483. ch 66, pp 174-178, (1998)

21.S Woods, A H Greenaway, A R Harvey, 'Optimal shape sensing using statistically derived basis sets', Unpublished 